edly erroneous ; but errors of diagnosis are as common as anything else, and all medical men are liable to them. We think it probable that few cases of real typhoid are now to be found South. A few months since, all diseases here had a typhoid proclivity; but they are mutating, and taking on remittent and intermittent phases, with some typhoid signs; and by the revolution of another year, we shall not probably have enough cases of typhoid fever to make mile posts in our counties.

In conclusion, we will return our sincere thanks to Dr. Fenner, for adding a trophy to nosology in the way of a correct and sensible name for the quinine treatment in typhoid fever-viz., Abortive.

Southerner.

\title{
PATHOLOGY OF POISONING-COINCIDENCES.
}

[Communicated for the Boston Medical and surgical Journal.]

As the pathology of poisoning is scarcely if at all touched on by systematic writers, the following, from Dr. Sequard, of Paris, becomes the more interesting :-

Influence of Poisons upon Animal Heat as a Cause of Death.-Dr. Sequard has published some peculiar views respecting his experiments with poisons, reducing animal heat. He says, he has seen death take place in a rabbit after a diminution of its heat of only 22 deg. of Fah. And he never observed any animal live after he had diminished its temperature more than 44 deg. of Fah. Accordingly as the heat is rapidly diminished, so is death produced in less time.

When by a wound, or poison, the temperature of a man is reduced many degrees, his life is in danger from that very cause. It is thus in cholera, and palsy.

In cases of poisoning, it has been found that the temperature of the poisoned person always decreased ; and M. Chossut, who injected opium into the veins of a dog, found the temperature diminish from 105 deg. to $62 \mathrm{deg}$. Fah. M. Sequard believes that many poisons may kill, simply by their action in reducing animal heat. He has found that some poisons, which kill animals when there is no obstacle to prevent the diminution of the body's temperature, will not destroy life when the temperature is sustained by artificial means to its normal degree.

Equal doses of poison were given to two animals, as much alike as possible. One was left in a room at a temperature of $46 \mathrm{deg}$. Fah., the other was kept in a place where the temperature was 75 degs., Fah. The first was dead after a certain number of hours; the other, that was kept warm, was generally cured very soon.

In cases of poisoning by opium, belladonna, tobacco, camphor, alcohol, acetic or oxalic acid, and many other poisons, physicians should labor to prevent a diminution of heat by keeping the patient as near as possible to the standard of $100 \mathrm{deg}$. Fah.

It is curious, in the history of coincidences, that simultaneous with the above, in the Old World, a method of treatment in the New World was instituted exactly conformable. . The bites of rattlesnakes, and other deadly reptiles, have been cured by enormous quantities of diffusible 
stimuli, instances of which have been given in this Journal, and others are almost daily occurring in the newspapers. An account lies before me of a negro who was bitten by a "copper head," and in the course of half an hour drank a quart of whiskey, and recovered. A number of similar cases have been lately recorded.

But perhaps the most curious of all is, that M. Sequard promulgated the theory, that stimulants, previously taken, would prevent the subsequent effects of poison; and that this theory was about the same time confirmed, on this side of the Atlantic, by a person, badly intoxicated, having been bitten by a rattlesnake, without any ill consequences whatever.

Now the history of the bite of mad-dogs shows frequent exemptions from hydrophobia; so frequent that Dr. P. S. Physick (whose lectures I attended), stated that nineteen twentieths of those who were bitten, experienced no ill effects at all. But as to rattlesnake bites, 1 have never known, heard, or read, of a single exemption, except in the instance above referred to.

Lebanon, Conn., July, 1853.

Josf.ph Comstock, M.D.

A SINGULAR CASE OF IMMUNITY FROM THF USUAL POISONOUS EFFECT OF ARSENOUS ACID.

[Communicated for the Boston Medical and Surgical Journal.]

THE occurrence, which is here briefly described, took place about thirty months since, in this city, and in the lapse of that time no circumstance has been observed, which could fix suspicions of intent or motives for the act, on any person.

At a boarding house with numerous inmates in $\mathrm{C} \longrightarrow$ street, the family, cook, and servants, partook of a substantial breakfast, of cooked meats, vegetables and coffee, on Sunday morning, and some hours after separated and attended service at different places of worship in the vicinity. Before the conclusion of the service, nearly every boarder was ill with a disposition to reject the contents of their stomachs, which in most cases could not be repressed. The master of the house and-his wife returned home, and having before resorted to the use of cold infusion of coffee, in slight disturbances, a portion of that, remaining after the morning meal, was freely drunk by both, without the expected curative effect being produced. As the inmates returned, sick and alarmed, the neighbors were called in, and inquiries made, which established the fact that the children, who had not partaken of the coffee, were in their usual good health. This, with other circumstances, pointed to the coffee as the cause of the sickness. Some of the friends tasted and drank a portion of the infusion, and becoming sick soon after, with the same symptoms, the evidence thus obtained was deemed satisfactory.

The next morning I received the coffee-pot with the remaining contents, for chemical analysis. It was sufficiently large to contain two gallons of fluid, and there remained some ten ounces of fluid, besides the grounds and partially extracted residue of the coffee. The fluid contained arsenous acid, apparently in as large proportion as exists in a saturated 